\title{
Screening for Diabetic Retinopathy: A Comparative Trial of Photography and Scanning Laser Ophthalmoscopy
}

\author{
P.J. Wilson ${ }^{a} \quad$ J.D. Ellis ${ }^{a} \quad$ C.J. MacEwen ${ }^{a} \quad$ A. Ellingford ${ }^{b} \quad$ J. Talbot $^{a} \quad$ G.P. Leese $^{b}$ \\ Departments of a Ophthalmology and ${ }^{\text {b }}$ Diabetes, Ninewells Hospital and Medical School, Dundee, UK
}

\section{Key Words}

Scanning laser ophthalmoscopy • Retinal photography •

Diabetic retinopathy screening

\begin{abstract}
Aims: To evaluate the sensitivity and specificity of wide-field scanning laser ophthalmoscopy (WSLO) in the detection of referable diabetic eye disease, and to compare its performance with digital retinal photography. Methods: Patients enrolled into the study underwent non-mydriatic WSLO imaging, then single- and dual-field mydriatic digital retinal photography, and examination with slit lamp biomicroscopy, the reference standard. Grading of retinopathy was performed in a masked fashion. Results: A total of 380 patients (759 eyes) were recruited to the study. Technical failure rates for dilated single-field retinal photography, dual-field retinal photography and undilated WSLO were $6.3,5.8$ and $10.8 \%$, respectively $(0.005<p<0.02$ for photography vs. WSLO). The respective indices for screening sensitivity were 82.9, 82.9 and $83.6 \%$ ( $p>0.2$ ). Specificity was $92.1,91.1$ and $89.5 \%$, respectively $(p>0.2)$. Conclusions: Sensitivity and specificity for WSLO were similar to retinal photography. The technical failure rate was greater for the WSLO used in this study.
\end{abstract}

Copyright $\odot 2010$ S. Karger AG, Basel (c) 2010 S. Karger AG, Basel

$0030-3755 / 10 / 2244-0251 \$ 26.00 / 0$

Fax +4161306 1234 E-Mail karger@karger.ch www.karger.com
Accessible online at:

www.karger.com/oph

\section{Introduction}

Various national committees recommend that patients with diabetes should undergo screening for retinopathy on an annual basis [1-3]. The method used should have a minimum sensitivity of $80 \%$ and a specificity of at least $95 \%$ for referable retinopathy $[4,5]$. The modality of choice in the UK is digital retinal photography using 45-degree fields. In Scotland, a single macula-centred field is taken of each eye, whereas in England and Wales this is supplemented with a disc-centred field [2, 6]. With either approach, the sensitivity for referable diabetic retinopathy has been demonstrated to lie within the range of $78-100 \%$ with specificity of $86-100 \%$, respectively [7-12]. This variation is due to differential use of mydriasis, definition of referable disease, and fields of photography, but overall retinal photography usually achieves the minimum standards for sensitivity, although it rarely achieves the required standard for specificity. In addition to screening precision, retinal photography must also contend with the possibility of technical failure, i.e. instances in which the image quality is not sufficient to permit grading. In routine practical eye screening programmes, the failure rate has been between 4.6 and $11.9 \%$ $[13,14]$, but in research projects it has varied from $1.3 \%$ with mydriasis to $36 \%$ without mydriasis $[7-11,15,16]$. This wide range is partly due to different use of mydriasis

Dr. Peter Wilson

Ward 25, Ninewells Hospital and Medical School

Dundee DD1 9SY (UK)

Tel. +44 1382660 111, ext. 34628, Fax +44 1382632893

E-Mail pj.wilson@nhs.net 


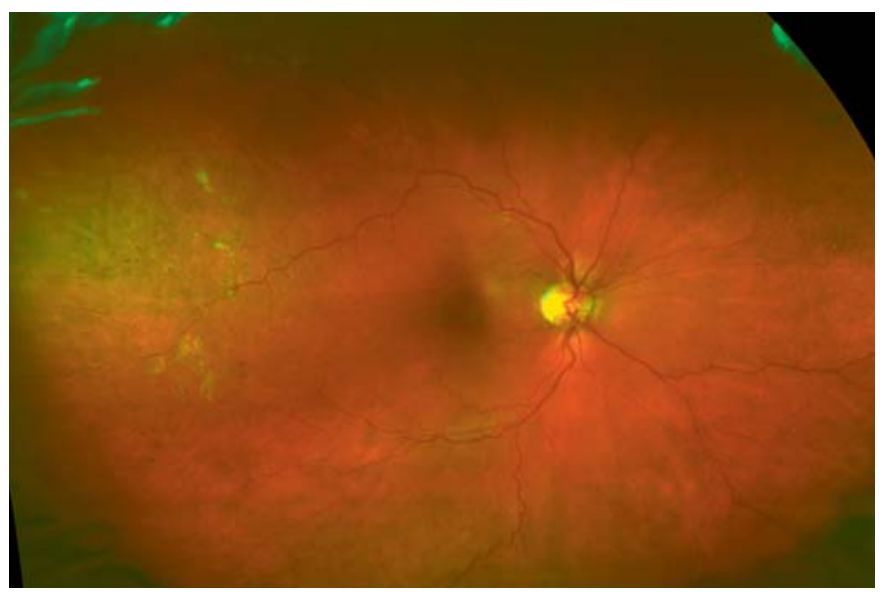

Fig. 1. WSLO image of mild non-proliferative diabetic retinopathy.

and partly to variations in definition of 'ungradable'. Such cases require review by other means, most commonly slit lamp examination by an ophthalmologist or optometrist $[1,3]$. This 2 -step screening process is costly, both to providers and to patients in terms of time, personnel and inconvenience. For these reasons, alternative and improved means of retinal screening should constantly be explored [17]. Wide-field scanning laser ophthalmoscopy (WSLO) utilises a fine laser beam which scans the retinal surface in a grid pattern in order to build up an image of the retina. The potential advantages of such a system include: (a) the possibility of an entirely non-mydriatic system; (b) the ability to resolve detail through some cataracts, leading to a lower rate of technical failure; (c) a wider angle of view - equivalent to an external angle of $136^{\circ}$.

A number of studies of WSLO in the clinical context have determined the ability to identify diabetic retinal changes $[18,19]$. However, to date no substantial trial of the utility of WSLO as a screening tool in clinical practice has been undertaken. In this study, we evaluated the sensitivity and specificity of WSLO for referable diabetic retinopathy, and sought to determine the role of WSLO in screening for diabetic retinopathy.

\section{Methods}

Subjects

Ethical approval for the study was obtained from the Tayside Committee for Research Ethics. The subjects were recruited from a cohort of patients with diabetes within the Tayside area over a 7-month period and were informed of the study by written invita-
Table 1. Scottish diabetic retinopathy grading scheme

\begin{tabular}{ll}
\hline $\begin{array}{l}\text { Pathology detected } \\
\text { No retinopathy }\end{array}$ & $\begin{array}{l}\text { Retinopathy } \\
\text { grade }\end{array}$ \\
\hline $\begin{array}{l}\text { Any of: } \\
\quad \begin{array}{l}\text { Microaneurysms } \\
\text { Dot haemorrhages }\end{array}\end{array}$ & $\mathrm{R} 1$ \\
$\quad \begin{array}{l}\text { Flame haemorrhages } \\
\geq 4 \text { blot haemorrhages in } 1 \text { hemifield or quadrant }\end{array}$ & $\mathrm{R} 2$ \\
\hline $\begin{array}{l}\text { Any of: } \\
\quad 4 \text { blot haemorrhages per hemifield or quadrant }\end{array}$ & $\mathrm{R} 3$ \\
$\begin{array}{l}\text { Abnormalities of venous calibre } \\
\text { Intraretinal micovascular abnormalities }\end{array}$ & $\mathrm{R} 4$ \\
\hline $\begin{array}{l}\text { Any of: } \\
\text { New active vessels at disc }\end{array}$ & \\
$\begin{array}{l}\text { New active vessels elsewhere } \\
\text { Vitreous haemorrhage }\end{array}$ & $\mathrm{R} 5$ \\
\hline $\begin{array}{l}\text { Enucleated } \\
\text { Not adequately visualised }\end{array}$ & $\mathrm{R} 6$ \\
\hline $\begin{array}{l}\text { Exudate }>1 \text { but } \leq 2 \text { DD from fovea } \\
\text { Exudate or blot haemorrhage } \leq 1 \text { DD from fovea }\end{array}$ & $\mathrm{M} 2$ \\
\hline
\end{tabular}

$\mathrm{DD}=$ Disc diameter

tion. Subjects were recruited from the general population in retinopathy screening and from the diabetic retinopathy clinic. Patients were excluded if they were unable to provide consent or undergo imaging due to learning difficulties or physical illness.

\section{Protocol}

All participants were recruited in Dundee, Scotland, and gave signed consent to study participation. All underwent monocular testing of visual acuity using a Snellen chart. Each eye was then imaged using a wide-field scanning laser ophthalmoscope (Optomap P200, Optos plc, Dunfermline, UK), an example of which is given in figure 1. Participants then underwent pupillary dilation with $1 \%$ tropicamide and were imaged using retinal photography (Canon CR-DGi with a Canon 20D SLR set at 2.0 megapixels, Canon Inc., Tokyo, Japan) after a 20-min delay to allow mydriasis to occur. Two 45-degree fields were taken with photography (one fovea-centred and one disc-centred field) as recommended by the English National Screening Programme for Diabetic Retinopathy [6]. The fovea-centred image was utilised for single-field scoring, whilst both were analysed in dual-field scoring. Finally, subjects were assessed with slit lamp biomicroscopy using a 78- or 90-dpt lens. Findings from the slit lamp were 
Table 2. Distribution of retinopathy/maculopathy per patient

\begin{tabular}{|c|c|c|c|c|}
\hline Retinopathy grade & Slit lamp & 1-field photography & 2-field photography & WSLO \\
\hline No retinopathy & $219(57.6)$ & $185(48.7)$ & $180(47.4)$ & $176(46.3)$ \\
\hline Background, no maculopathy & $75(19.7)$ & $78(20.5)$ & $82(21.6)$ & $65(17.1)$ \\
\hline No referable retinopathy, observable maculopathy & $8(2.1)$ & $8(2.1)$ & $8(2.1)$ & $9(2.4)$ \\
\hline Referable disease & $78(20.5)$ & $85(22.4)$ & $88(23.2)$ & $89(23.4)$ \\
\hline Technical failure (R6) & - & $24(6.3)$ & $22(5.8)$ & $41(10.8)$ \\
\hline Total & $380(100.0)$ & $380(100.0)$ & $380(100.0)$ & $380(100.0)$ \\
\hline
\end{tabular}

Results are numbers of patients, with percentages in parentheses.

Table 3. Comparison between grading of patients by slit lamp and imaging

a Retinopathy

\begin{tabular}{|c|c|c|c|c|c|c|c|c|c|c|c|c|c|c|c|}
\hline \multirow[t]{2}{*}{ Slit lamp } & \multicolumn{3}{|l|}{ R0 } & \multicolumn{3}{|l|}{$\mathrm{R} 1$} & \multicolumn{3}{|l|}{$\mathrm{R} 2$} & \multicolumn{3}{|l|}{$\mathrm{R} 3$} & \multicolumn{3}{|l|}{$\mathrm{R} 4$} \\
\hline & $\mathrm{P} 1$ & $\mathrm{P} 2$ & WSLO & P1 & $\mathrm{P} 2$ & WSLO & $\mathrm{P} 1$ & P2 & WSLO & P1 & $\mathrm{P} 2$ & WSLO & $\mathrm{P} 1$ & $\mathrm{P} 2$ & WSLO \\
\hline R0 & 177 & 171 & 163 & 7 & 8 & 14 & 0 & 0 & 0 & 2 & 2 & 2 & 0 & 0 & 0 \\
\hline $\mathrm{R} 1$ & 28 & 34 & 26 & 72 & 70 & 53 & 1 & 1 & 2 & 8 & 8 & 6 & 3 & 2 & 2 \\
\hline $\mathrm{R} 2$ & 0 & 0 & 2 & 3 & 4 & 7 & 1 & 1 & 0 & 4 & 5 & 5 & 1 & 0 & 1 \\
\hline R3 & 2 & 2 & 2 & 7 & 8 & 12 & 2 & 2 & 2 & 6 & 14 & 17 & 4 & 6 & 5 \\
\hline R4 & 0 & 0 & 2 & 1 & 2 & 0 & 0 & 0 & 0 & 4 & 5 & 4 & 10 & 10 & 9 \\
\hline R6 & 15 & 15 & 27 & 11 & 9 & 15 & 0 & 0 & 0 & 1 & 1 & 1 & 0 & 0 & 1 \\
\hline
\end{tabular}

b Maculopathy

\begin{tabular}{|c|c|c|c|c|c|c|c|c|c|}
\hline \multirow[t]{2}{*}{ Slit lamp } & \multicolumn{3}{|l|}{ M0 } & \multicolumn{3}{|c|}{ M1 } & \multicolumn{3}{|c|}{ M2 } \\
\hline & P1 & $\mathrm{P} 2$ & WSLO & $\mathrm{P} 1$ & P2 & WSLO & P1 & P2 & WSLO \\
\hline M0 & 272 & 274 & 250 & 5 & 4 & 6 & 4 & 4 & 7 \\
\hline M1 & 9 & 9 & 13 & 4 & 4 & 4 & 0 & 0 & 0 \\
\hline M2 & 25 & 25 & 27 & 3 & 4 & 3 & 34 & 34 & 29 \\
\hline R6 & 22 & 20 & 38 & 1 & 1 & 0 & 1 & 1 & 3 \\
\hline
\end{tabular}

P1 = Single-field photography; P2 = dual-field photography. Results are numbers of patients. Figures in italics are false-negative, those in bold false-positive imaging.

recorded on a standardised sheet. The WSLO was performed by a trained nurse, the photography by an ophthalmic photographer and the slit lamp assessment by one consultant or one trainee ophthalmologist.

All retinas/images were graded in a masked fashion, using a common scoring system. All imaging was graded by an ophthalmology research fellow (P.J.W.), the photography at magnification levels of $100 \%$, and the WSLO images at $125 \%$. The grading system utilised the Scottish diabetic retinopathy grading scheme [20], which is based on the Early Treatment Diabetic Retinopathy Study, including the 4:2:1 rule for severe non-proliferative disease. The grader determined the presence or absence of key pathologies and, where appropriate, the number of lesions or the distance from the fovea. The pathology checklist was used to calculate retinopathy and maculopathy scores for each eye. Referable retinopathy was defined as retinopathy of grade 3 or 4 (R3/R4) or maculopathy of grade 2 (M2) (table 1). To obtain a unified score 'per patient', the eye with the more severe pathology was recorded. If images for one eye were deemed ungradable (R6), then the patient was scored as R6, unless the contralateral eye was scored as referable retinopathy or referable maculopathy. The definition used for ungradable images was that agreed by the Scottish Diabetic Retinopathy Screening Programme: any image with visible referable disease is deemed gradable; an adequate image has a sufficient field of view (the fovea 
Table 4. Sensitivity and specificity for retinopathy and maculopathy, proportion and $95 \% \mathrm{CI}$ (in parentheses)

\begin{tabular}{|c|c|c|c|c|c|c|}
\hline & \multicolumn{6}{|c|}{ Scores per patient } \\
\hline & \multicolumn{2}{|c|}{ 1-field photo } & \multicolumn{2}{|c|}{2 -field photo } & \multicolumn{2}{|l|}{ WSLO } \\
\hline Slit lamp & referable & $\begin{array}{l}\text { non- } \\
\text { referable }\end{array}$ & referable & $\begin{array}{l}\text { non- } \\
\text { referable }\end{array}$ & referable & $\begin{array}{l}\text { non- } \\
\text { referable }\end{array}$ \\
\hline \multicolumn{7}{|l|}{ Referable disease (R3/R4/M2) } \\
\hline Image referable, $\mathrm{n}$ & 63 & 22 & 63 & 25 & 61 & 28 \\
\hline Image non-referable, $\mathrm{n}$ & 13 & 258 & 13 & 257 & 12 & 238 \\
\hline Technical failure (R6), n & 2 & 22 & 2 & 20 & 5 & 36 \\
\hline Technical failure (R6), \% & $6.3(5.1-$ & & $\mathbf{5 . 8}(4.6$ & & $10.8(9.2$ & \\
\hline Sensitivity, \% & $82.9(74.4$ & & $82.9(74$ & & $83.6(75$ & \\
\hline Specificity, \% & $92.1(89.0$ & & $91.1(87$. & & $89.5(85$ & \\
\hline$\kappa$ & $0.72(0.63$ & & $0.70(0.6$ & & $0.67(0.5$ & \\
\hline \multicolumn{7}{|c|}{ All referable cases (R3/R4/R6/M2) } \\
\hline Image referable, $\mathrm{n}$ & 65 & 44 & 65 & 45 & 66 & 64 \\
\hline Image non-referable, $\mathrm{n}$ & 13 & 258 & 13 & 257 & 12 & 238 \\
\hline Sensitivity, \% & $83.3(75.1$ & & $83.3(75$ & & $84.6(76$ & \\
\hline Specificity, \% & $85.4(81.5$ & & $85.1(81$ & & $78.8(74$ & \\
\hline к & $0.60(0.51$ & & $0.59(0.5$ & & $0.51(0.4$ & \\
\hline \multicolumn{7}{|c|}{ Referable retinopathy (R3/R4 only) } \\
\hline Image referable, $\mathrm{n}$ & 34 & 12 & 35 & 14 & 35 & 18 \\
\hline Image non-referable, $\mathrm{n}$ & 18 & 289 & 17 & 289 & 16 & 267 \\
\hline Technical failure (R6), n & 1 & 26 & 1 & 24 & 2 & 42 \\
\hline Technical failure (R6), \% & $7.1(5.8$ & & $\mathbf{6 . 6}(5.3$ & & $11.6(9.9$ & \\
\hline Sensitivity, \% & $65.4(52.5$ & & $67.3(54$ & & $68.6(55$ & \\
\hline Specificity, \% & $96.0(93.8$ & & $95.4(93$. & & $93.7(90$ & \\
\hline к & $0.64(0.52$ & & $0.63(0.5$ & & $0.60(0.4$ & \\
\hline \multicolumn{7}{|l|}{ All diabetic eye diseases } \\
\hline Image referable, $\mathrm{n}$ & 142 & 29 & 143 & 35 & 130 & 33 \\
\hline Image non-referable, $\mathrm{n}$ & 10 & 175 & 11 & 169 & 17 & 159 \\
\hline Technical failure (R6), n & 9 & 15 & 7 & 15 & 14 & 27 \\
\hline Technical failure (R6), \% & $6.3(5.1$ & & $\mathbf{5 . 8}(4.6$ & & $10.8(9.2$ & \\
\hline Sensitivity, \% & $93.4(89$ & & $92.9(88$ & & $88.4(83$ & \\
\hline Specificity, \% & $85.8(81$ & & $82.8(77$ & & $82.8(77$ & \\
\hline$\kappa$ & $0.78(0.7$ & & $0.74(0.6$ & & $0.70(0.6$ & \\
\hline
\end{tabular}

Bold indicates significant difference between photography and WSLO: ${ }^{*} \mathrm{p}=0.02,{ }^{* *} \mathrm{p}=0.04,{ }^{* *} \mathrm{p}=0.005$, n.s. $=\mathrm{p}>0.05$.

is at least 2 disc diameters from the edge of the image, and the optic disc is fully seen) and sufficient clarity (third-generation vessels around the fovea are visible) [20].

Slit lamp examination was used as the 'reference standard' examination and has previously been shown to be as effective as 7field stereophotography, whilst also being much less prone to media-opacity-related failure [15]. Sensitivity and specificity were calculated for digital retinal photography and WSLO when compared to slit lamp examination. Calculations were made before and after excluding ungradable images from the analysis. Comparisons between the two methods were assessed statistically using $\chi^{2}$ calculations on SPSS (Chicago, Ill., USA).

\section{Results}

Four hundred and five patients were invited to participate, of whom 22 declined, and 3 were too infirm to participate. Therefore, 380 patients $(93.8 \%$ of those invited) were recruited to the study, with a median age of 67.4 years (range 21-94), of whom 230 (60.5\%) were male. Of the 380 patients, 205 were from the diabetic retinopathy clinic, and 175 were from the screening clinic.

Of all patients screened, 219 (57.6\%) had no retinopathy, 75 (19.7\%) had background retinopathy without mac- 
ulopathy (R1/R2), 8 (2.1\%) had observable maculopathy (M1), and $78(20.5 \%)$ had referable retinopathy or maculopathy (R3/R4 or M2; table 2). For the purposes of context and comparison, during the same time period in the screening programme across Tayside, $59.2 \%$ of patients had no retinopathy, $30.0 \%$ had background retinopathy without maculopathy, $2.8 \%$ had observable maculopathy, and $6.9 \%$ had referable retinopathy or maculopathy. The technical failure rate for the region was 3.3\%.

The grading assigned to each patient is shown in table 3, with differences in referability highlighted to demonstrate false-positive and false-negative referrals. The majority of false-negative retinopathy referrals were due to venous beading (1-field/2-field/WSLO $=61.1 /$ $58.8 / 62.5 \%$, n.s.) and/or intraretinal microvascular abnormalities (38.9/41.2/25.0\%, n.s.). False-positive retinopathy referrals were also associated with intraretinal microvascular abnormalities $(66.7 / 71.4 / 33.3 \%$, n.s.) and/ or venous beading $(41.7 / 42.9 / 72.2 \%$, n.s.).

The number of ungradable images with undilated WSLO was greater than that obtained with dilated 2-field retinal photography ( 10.8 vs. $5.8 \%, \mathrm{p}=0.005)$ and with dilated 1-field retinal photography (10.8 vs. $6.3 \%, \mathrm{p}=$ $0.02)$. WSLO technical failure was documented in 54 eyes (47 patients, 6 of whom were scored as referable, due to disease in the contralateral eye). For the 175 patients from the screening clinic, the technical failure rate was much lower: $2.9 \%$ (95\% confidence interval, $\mathrm{CI}=1.6-4.1 \%$ ) for single- and dual-field photography, and 4.0\% (95\% CI = 2.5-5.5\%) for WSLO (n.s.).

The sensitivity for detection of referable disease with WSLO was $83.6 \%$ (95\% CI $=75.1-92.1 \%)$. Specificity was $89.5 \%$ (95\% CI $=85.8-93.2 \%)$. This was not significantly different to either 1- or 2-field retinal photography (table 4).

An alternative method of calculation is to include the ungradable images and count as referable all patients either with referable disease or ungradable images (table 4, 'all referable cases'). Utilising this method, sensitivity remained similar between the groups, but specificity fell more in the WSLO group, due to the inclusion of a greater number of technical failures $(\mathrm{p}=0.04$ compared to single-field photography, n.s. compared to dual-field photography). There were no significant differences between all 3 modalities in the detection of the presence of 'any retinopathy'.

The type of lesion identified by each imaging modality was also assessed. Single-field photography was able to identify microaneurysms in $95.9 \%$ of cases that slit lamp had done so, whereas WSLO achieved this in only
$79.2 \%(\mathrm{p}<0.001)$, a difference that appeared to be due to the lower resolution. On the other hand, WSLO was able to detect blot haemorrhages in $94.0 \%$ of cases, compared to $79.7 \%$ in single-field photography and $81.2 \%$ in dualfield photography $(\mathrm{p}<0.03)$. With regard to referable lesions, photography had a tendency to miss new vessels elsewhere more often than WSLO (30.8\% sensitivity compared to $38.5 \%$, n.s.), but outperformed WSLO in the identification of macular blot haemorrhages (83.3 vs. $36.3 \%, \mathrm{p}<0.05)$.

Single-field photography was the quickest to grade (average 64 s/eye), followed by 2 -field photography (average 94 s) and WSLO (average 106 s), with $p<0.001$ between all 3 groups.

\section{Discussion}

This study has demonstrated that WSLO achieved a sensitivity of $83.6 \%$ in screening for diabetic retinopathy, compared to $82.9 \%$ for digital photography, although there was no significant difference between these values. WSLO imaging without mydriasis proved to have a higher rate of ungradable images than routine photography with mydriasis. Therefore, in screening practice, WSLO may require selected mydriasis, but in fewer patients than for photography. WSLO without mydriasis obviates the associated disadvantages of mydriasis, which include drug administration and cost, delay in capturing images, in addition to multiple patient-related issues such as driving difficulties and blurred vision $[2,21]$. WSLO was used without mydriasis and demonstrated a technical failure rate of $10.8 \%$. Some of these failures may have been due to a procedural failure to review the images at the time of capture; adjustment of capture settings can overcome some of the issues associated with poor image quality. It should be noted that when retinal cameras are used without mydriasis, the technical failure rates may be as high as $20-36 \%[8,16]$, although in routine practice, with selective use of mydriasis, the failure rate can be around $5-12 \%[13,14]$. The use of mydriasis with WSLO may reduce the number of technical failures to a similar degree. We did not test this, however. Furthermore, a relatively low technical failure rate for digital photography in this study was only achieved on the software platform used for grading WSLO images. This software facilitated the adjustment and enhancement of images in order to maximise the level of detail visible. Such software is not usually available, and photographic grading on the platform used in routine clinical service led to a technical failure rate of $10.7 \%$, which was comparable to 
the WSLO at $10.8 \%$. The high rate of technical failures both for digital photography and for WSLO may largely be explained by the fact that many patients were recruited from the diabetic retinopathy clinic, many of whom had been referred to the clinic solely due to difficulties in photographic screening. This recruitment process follows the methodology of previous studies $[15,16]$ and also explains the high prevalence of retinopathy in the current study.

A wide angle of view resulted in detection of lesions with WSLO that were outwith the field of routine photography. The WSLO covers an area greater than 7-field photography, which is generally accepted as the de facto reference standard of retinal examination. However, in the screening context, the relevance of detecting peripheral lesions beyond the 45 -degree angle of the fovea is currently uncertain and controversial.

There are, however, several practical issues and considerations which must be addressed before WSLO may be widely accepted and adopted as a screening modality. Firstly, screening is often conducted in peripheral geographical locations with mobile equipment [4], and the role of WSLO may be limited in these circumstances. Certainly, WSLO has been incorporated into a mobile unit, but this has not been formally trialled in the context of diabetic screening. For this reason WSLO would probably need to be confined to static sites initially.

Secondly, the wide angle of view means that the available pixels are spread over a greater area, resulting in lower pixel density. The English National Screening Committee previously recommended that any camera should have at least 20 pixels/degree in both axes [22]. Although this has since been recognised as a flawed surrogate for smallest resolvable lesion, no suitable alternative specification has been identified. The Canon camera operated at a resolution of 2.0 megapixels, equating to approximately 28.1 pixels/degree. The WSLO used in this study has 2 sensors of 4 megapixels each, covering a horizontal external angle of $136^{\circ}$, and a vertical external angle of $96^{\circ}$. This achieves a resolution of 14.6 pixels/degree in the horizontal plane and 20.7 in the vertical. However, it must be recognised that describing resolution in 'pixels per degree' takes no account of the distribution of pixel density across the image, which on the WSLO is greatest centrally. Furthermore, it is a measure developed for digital photography which uses charge-coupled devices or a complementary metal oxide semiconductor, in contrast to WSLO which uses an avalanche photo diode system which has a different technical operation and performance.

Adequate resolution is essential in order to detect small lesions. Poor resolution results in either diagnostic uncertainty (loss of precision) or failure to detect the lesion at all (loss of sensitivity). Diagnostic uncertainty can be improved by training, experience and familiarity of the grader with the imaging modality. These practical difficulties of WSLO, including lower resolution, appear to have been compensated for by other benefits, given the comparable sensitivity and specificity in this study. These benefits may include improved detection of peripheral lesions, resistance to chromatic aberration and scatter, resulting in improved lesion contrast. It is noteworthy that the WSLO was less effective at detecting microaneurysms but was better at detecting peripheral blot haemorrhages, which are clinically more important.

However, significantly more time is spent on analysis of the WSLO image (106 s/eye) than with either dual-field digital photography (94 s/eye) or single-field photography (64 s/eye). This is due to a combination of diagnostic uncertainty, a larger area of the retina to grade, separate analysis of retinal and choroidal layers and the requirement for adjustment and enhancement of the image [23], a process not required to the same degree for retinal photography. The differences may become less important if automated grading becomes adopted for future practice [24, 25].

Future generations of WSLO may address some of these issues, including higher resolution of images, greater image enhancement and intensity associated with lower rates of technical failure, better ergonomics for patient and photographer, and more efficient review software. Whether the newer model WSLO will deliver clinical improvements in line with the technological improvements should be the subject of future study. Currently the purchase or lease cost of WSLO is greater than for retinal cameras, but like retinal cameras, the costs are likely to decrease if more are produced and used. Regardless of the resolving ability of any imaging system, an investment in improved infrastructure and programme administration is essential to optimise the contribution of these technologies to a rapidly growing field.

In summary, the sensitivities of retinal photography and WSLO for referable diabetic retinopathy were $82.9 \%$ and $83.6 \%$, respectively. If this level of sensitivity is agreed to be acceptable for screening, then both modalities could be appropriately used for screening purposes.

\section{Acknowledgements}

We would like to thank Prof. Peter Donnan for his support in the statistical analysis of the data. We acknowledge that this work was supported by an unattributed research grant from Optos plc. 


\section{References}

1 Garvican L, Clowes J, Gillow T: Preservation of sight in diabetes: developing a national risk reduction programme. Diabet Med 2000;17:627-634

2 Facey K, Cummins E, Macpherson K, Morris A, Reay L, Slattery J: Organisation of services for diabetic retinopathy screening. Health Technology Assessment Report 1. Glasgow, Health Technology Board for Scotland, 2002.

>3 Fong DS, Aiello L, Gardner TW, King GL, Blankenship G, Cavallerano JD, Ferris FL 3rd, Klein R: Retinopathy in diabetes. Diabetes Care 2004;27(suppl 1):S84-S87.

$\checkmark 4$ Taylor R: Practical community screening for diabetic retinopathy using the mobile retinal camera: report of a 12 centre study. British Diabetic Association Mobile Retinal Screening Group. Diabet Med 1996;13:946-952.

5 British Diabetic Association: Retinal Photography Screening for Diabetic Eye Disease. London, British Diabetic Association, 1997.

6 Workbook 4 of the English National Screening Programme for Diabetic Retinopathy. http://www.retinalscreening.nhs.uk/pages (accessed August 12, 2009).

$>7$ Olson JA, Strachan FM, Hipwell JH, Goatman KA, McHardy KC, Forrester JV, Sharp PF: A comparative evaluation of digital imaging, retinal photography and optometrist examination in screening for diabetic retinopathy. Diabet Med 2003;20:528-534.

$\checkmark 8$ Scanlon PH, Malhotra R, Thomas G, Foy C, Kirkpatrick JN, Lewis-Barned N, Harney B, Aldington SJ: The effectiveness of screening for diabetic retinopathy by digital imaging photography and technician ophthalmoscopy. Diabet Med 2003;20:467-474.

-9 Harding SP, Broadbent DM, Neoh C, White MC, Vora J: Sensitivity and specificity of photography and direct ophthalmoscopy in screening for sight threatening eye disease: the Liverpool Diabetic Eye Study. Br Med J 1995;311:1131-1135.
10 Lin DY, Blumenkranz MS, Brothers RJ, Grosvenor DM: The sensitivity and specificity of single-field nonmydriatic monochromatic digital fundus photography with remote image interpretation for diabetic retinopathy screening: a comparison with ophthalmoscopy and standardized mydriatic color photography. Am J Ophthalmol 2002;134:204-213.

11 Lopez-Bastida J, Cabrera-Lopez F, SerranoAguilar P: Sensitivity and specificity of digital retinal imaging for screening diabetic retinopathy. Diabet Med 2007;24:403-407.

12 Perrier M, Boucher MC, Angioi K, Gresset JA, Olivier S: Comparison of two, three and four 45 degrees image fields obtained with the Topcon CRW6 non-mydriatic camera for screening for diabetic retinopathy. Can J Ophthalmol 2003;38:569-574.

13 Leese GP, Morris AD, Swaminathan K, Petrie JR, Sinharay R, Ellingford A, Taylor A, Jung RT, Newton RW, Ellis JD: Implementation of national diabetes retinal screening programme is associated with a reduced referral rate to ophthalmology. Diabet Med 2005;22:1112-1115.

14 Philip S, Cowie LM, Olson JA: The impact of the Health Technology Board for Scotland's grading model on referrals to ophthalmology services. Br J Ophthalmol 2005;89:891896.

15 Scanlon PH, Malhotra R, Greenwood RH, Aldington SJ, Foy C, Flatman M, Downes S: Comparison of two reference standards in validating two field mydriatic digital photography as a method of screening for diabetic retinopathy. Br J Ophthalmol 2003;87: 1258-1263.
16 Murgatroyd H, Ellingford A, Cox A, Binnie M, Ellis JD, MacEwen CJ, Leese GP: Effect of mydriasis and different field strategies on digital image screening of diabetic eye disease. Br J Ophthalmol 2004;88:920-924.

17 Leese GP, Ellis JD: Quality assurance for diabetic retinal screening. Diabet Med 2007;24: 579-581.

18 Mayer H: The Optos Panoramic 200 scanning laser ophthalmoscope: advancing optometric practice. Clin Refract Optom 2004; 15:156-162.

19 Friberg TR, Pandya AN, Eller AW: Nonmydriatic panoramic fundus imaging using a non-contact scanning laser-based system. Ophthalmic Surg Lasers Imag 2003;34:488497.

20 Scottish diabetic retinopathy grading scheme version 1.1. 2007. http://www.ndrs. scot.nhs.uk/ClinGrp/ (accessed August 12, 2009).

21 Jude E, Ryan B, O’Leary J, Gibson JM, Dodson PM: Pupillary dilatation and driving in diabetic patients. Diabet Med 1998;15:143147.

22 The Liverpool Declaration 2005. Report of conference, version 2, Liverpool, 2006. www. drscreening2005.org.uk (accessed August 12, 2009)

23 Khandhadia S, Madhusudhana KC, Kostakou A, Forrester JV, Newsom RS: Use of Optomap for retinal screening within an eye casualty setting. Br J Ophthalmol 2009;93: 52-55.

24 Larsen N, Godt J, Grunkin M, Lund-Andersen H, Larsen M: Automated detection of diabetic retinopathy in a fundus photographic screening population. Invest Ophthalmol Vis Sci 2003;44:767-771.

-25 Philip S, Fleming AD, Goatman KA, Fonseca S, McNamee P, Scotland GS, Prescott GJ, Sharp PF, Olson JA: The efficacy of automated 'disease/no disease' grading for diabetic retinopathy in a systematic screening programme. Br J Ophthalmol 2007;91:15121517. 